\title{
The Gender Effect of Health-Related Quality of Life in Hemodialysis Patients
}

\author{
Eghlim Nemati ${ }^{1}$, Mohsen Motalebi ${ }^{1{ }^{1 *}}$ \\ ${ }^{1}$ Nephrology and Urology Research Center, Baqiyatallah University of Medical Sciences, Tehran, IR Iran \\ ${ }^{*}$ Corresponding author: Mohsen Motalebi, Nephrology and Urology Research Center, Baqiyatallah University of Medical Sciences, Molla Sadra Ave, Vanak Sq., Tehran, IR Iran. Tel: +98- \\ 2181262073, Fax: +98-2181262073, E-mail: dr.motalebi@ymail.com.
}

Received: November 2, 2013; Revised: November 6, 2013; Accepted: December 1, 2013

Keywords: Quality of Life; Gender Identity; Renal Dialysis

\section{Dear Editor,}

We read with great interest the recent published outstanding article in your esteemed journal by Rostami et al.(1) entitled "Health-related quality of life in hemodialysis patients: an Iranian multi-center study". The message of this valuable and huge study focused on drawing the attention to the biographic, socio-economic, and biochemical factors, which can influence on health-related quality of life (HRQoL) of hemodialysis (HD) patients.

The impact of gender on quality of life (QoL) has remained a challenge yet. Although Rostami and coworkers (1) showed that men had better QoL than women, other studies found that females had better (2) or equal (3) QoL when compared to males. There are some important subjects to note about gender effects on QoL which can help this matter: 1 ) higher prevalence and severity of psychological disorders such as major depressive disorder and anxiety disorder in females cause poorer HRQoL in women than men (4).2) It seems females are more capable than males in providing and receiving emotional support. 3) Women benefit more from family support, but men receive more support from health care professionals (5). 4) Females with chronic kidney disease (CKD) have lower handgrip force, lower exercise tolerance, greater arm fat region, and less muscle area than males (6). 5) Higher prevalence of viral hepatitis in males on hemodialysis (7) can influence HRQoL in them. 6) It has been shown that other chronic disorders in HD patients can influence HRQoL (3). Anyway, it is important to note that there is a different for perception of QoL among various countries, areas, religious, ethnic groups, and races between both genders. It seems that a meta-analysis is needed to evaluate whether gender has any influence on QoL in HD patients.

Although Rostami et al.(1) showed no difference between QoL among HD patients with and without diabetes, Anees et al. (8) found the QOL of HD patients with diabetes was poor in comparison to patients without diabetes. In addi- tion, they showed HD patients with non-diabetic causes of CKD had a better QOL in physical health scope than HD patients with diabetes (8). Patients with diabetes have multiorgan damage such as vision and cardiac problem, renal failure, cerebrovascular and peripheral vascular disease, which can lead to amputation and diminished physical health. Moreover, high rate of sleep disorders were demonstrated in patients with diabetes (9). Hence, it seems that HD patients who suffer from diabetes have worse QoL than others.

We agree that QoL in HD patients are poorer than normal population. It seems that besides preparing these patients for kidney transplantation and treatment of biochemical disorders, HD patients counseling can improve QoL. Abraham and coworkers (10) conducted a study to evaluate the effect of patients counseling on QoL and concluded patients counseling would improve QoL of HD patients in all domains; therefore, we can help these patients with our attention and counseling in addition to focus on treatment only.

\section{Authors' Contribution}

1- Study concept and design: Mohsen Motalebi. 2- Drafting of the manuscript: Eghlim Nemati, Mohsen Motalebi. 3- Critical revision of the manuscript for important intellectual content: Eghlim Nemati, Mohsen Motalebi. 4- Administrative, technical, and material support: Eghlim Nemati , Nohsen Motalebi. 5- Study supervision: Eghlim Nemati.

\section{Financial Disclosure}

The authors declare no conflict of interest.

\section{References}

1. Rostami Z, Einollahi B, Lessan-Pezeshki M, Soleimani Najaf Abadi A, Mohammadi Kebar S, Shahbazian H, et al. Health-related quality of life in hemodialysis patients: an Iranian multi-center study. 
Nephrourol Mon. 2013;5(4):901-12.

2. Bayoumi M, Al Harbi A, Al Suwaida A, Al Ghonaim M, Al Wakeel J, Mishkiry A. Predictors of quality of life in hemodialysis patients. Saudi J Kidney Dis Transpl. 2013;24(2):254-9.

3. Pakpour AH, Saffari M, Yekaninejad MS, Panahi D, Harrison AP, Molsted S. Health-related quality of life in a sample of Iranian patients on hemodialysis. Iran J Kidney Dis. 2010;4(1):50-9.

4. Peng YS, Huang JW, Hung KY, Lin BS, Lin CY, Yang CS, et al. Women on hemodialysis have lower self-reported health-related quality of life scores but better survival than men. J Nephrol. 2013;26(2):366-74.

5. Fife BL, Kennedy VN, Robinson L. Gender and Adjustment to Cancer. J Psychosocial Oncol. 1994;12(1-2):1-21.

6. Constantin Teodosiu D, Young S, Wellock F, Short AH, Burden RP, Morgan AG, et al. Gender and age differences in plasma car- nitine, muscle strength, and exercise tolerance in haemodialysis patients. Nephrol Dialysis Transplant. 2002;17(10):1808-13.

7. Rostami Z, Lessan Pezeshki M, Soleimani Najaf Abadi A, Einollahi B. Health related quality of life in Iranian hemodialysis patients with viral hepatitis: changing epidemiology. Hepat Mon 2013;13(6):e9611.

8. Anees M, Hameed F, Mumtaz A, Ibrahim M, Saeed Khan MN. Dialysis-related factors affecting quality of life in patients on hemodialysis. Iran J Kidney Dis. 2011;5(1):9-14.

9. Turkmen K, Erdur FM, Guney I, Gaipov A, Turgut F, Altintepe L, et al. Sleep quality, depression, and quality of life in elderly hemodialysis patients. Int J Nephrol Renovasc Dis. 2012;5:135-42.

10. Abraham S, Ramachandran A. Estimation of quality of life in haemodialysis patients. Indian J Pharm Sci. 2012;74(6):583-7. 